\title{
A Study of Creatine Metabolism in Diseases Causing Muscle Wasting *
}

\author{
Coy D. Fitch and David W. Sinton $\dagger$ \\ (From the Departments of Medicine and Biochemistry and the Division of Neurology, \\ University of Arkansas School of Medicine, Little Rock, Ark.)
}

The biochemical lesion responsible for the muscle wasting of muscular dystrophy remains obscure despite many studies of the abnormalities of metabolism that occur in the disease. Since primarily striated muscle is involved, attention may be focused on abnormalities of the distinctive features of muscle. One of these features is a high concentration of creatine. Over $90 \%$ of total body creatine is present in muscle, where its concentration is approximately $400 \mathrm{mg}$ per $100 \mathrm{~g}$ wet weight (1). This may be compared to a concentration of $0.5 \mathrm{mg}$ or less per $100 \mathrm{ml}$ of plasma $(2,3)$. Much of the creatine is present as phosphocreatine, a compound important for energy metabolism, particularly of skeletal muscle. Hence, an abnormality of creatine metabolism might preferentially affect muscle.

An abnormality of creatine metabolism in muscular dystrophy patients is indicated by their increased excretion of urine creatine, decreased excretion of urine creatinine, and reduced concentration of muscle creatine (4-9). The reason for these changes is poorly understood, even though the work of Benedict and associates (10) provides evidence concerning the origin of the urine creatine. In studies using isotopically labeled glycine, these authors found that some of the creatine in the urine of patients with progressive muscular dystrophy was newly synthesized and had not entered skeletal muscle. This finding suggests that the biosynthesis of creatine exceeds the amount entering muscle, but it does not account

\footnotetext{
* Submitted for publication July 29, 1963; accepted November 14, 1963.

This investigation was supported by grants NB-04339, AM-03615, and FR-49 from the National Institutes of Health, Bethesda, Md.

Preliminary reports of this investigation appeared in the J. Lab. clin. Med. 1962, 60, 874, and Neurology 1963, 13, 347.

$\dagger$ Died, January 23, 1964.
}

for the reduced concentration of creatine in the muscle.

On the basis of present knowledge of creatine metabolism, the turnover of muscle creatine can be studied using isotopically labeled creatine. Creatinine, formed nonenzymatically in the body $(1,11)$, is the end product of creatine metabolism (12-15). Since muscle contains most of the creatine in the body, creatinine may be assumed to be derived primarily from muscle creatine. This assumption is supported by evidence from animal studies $(12,13)$, and additional support is given by the present report. Therefore, the change in isotope content of urine creatinine is a measure of the change in isotope content of muscle creatine.

The purpose of this report is to describe studies of creatine turnover in patients with muscular dystrophy and to compare the findings with those of patients with other diseases of muscle. Evidence of an impaired ability of muscle to retain creatine was found only in the patients with muscular dystrophy.

\section{Methods}

The turnover of creatine was studied in vivo after body creatine was labeled with creatine- $C^{\mathbf{1 4}}$. After the administration of creatine- $\mathrm{C}^{\mathbf{1 4}}$ the disappearance of the radioactive label from urine creatinine as well as from blood, skeletal muscle, and urine creatine was followed. In addition, routine studies of the excretion of creatine and creatinine were performed.

Of the seven patient volunteers, five had primary muscle disease, one had amyotrophic lateral sclerosis, and one had a primary refractory anemia with no demonstrable disease of muscle. Both Caucasians and $\mathrm{Ne}$ groes were studied. None had an infection when the studies were begun, nor did any patient develop a major illness during the studies. Electromyography and histologic examination of muscle confirmed the clinical diagnosis in each patient that had wasting of muscle; other clinical information is given in Table I.

In an attempt to control the effect of diet on creatine 
TABLE I

Clinical data

\begin{tabular}{|c|c|c|c|c|}
\hline Patient & Diagnosis & Sex & Age & Comments \\
\hline R.B. & Primary refractory anemia & $\mathbf{M}$ & 77 & No abnormalities of skeletal muscle. \\
\hline H.G. & $\begin{array}{l}\text { Amyotrophic lateral } \\
\text { sclerosis }\end{array}$ & M & 43 & $\begin{array}{l}\text { Onset of weakness at age } 40 \text {. Progression of weakness and wast- } \\
\text { ing apparent during the study. }\end{array}$ \\
\hline H.C. & Late onset myopathy & M & 47 & $\begin{array}{l}\text { Onset of weakness at age } 40 \text {. Also had discoid lupus erythema- } \\
\text { tosus (LE) and had been treated with gold and bismuth. } \\
\mathrm{LE} \mathrm{phenomenon} \mathrm{not} \mathrm{present.} \mathrm{Protein-bound} \mathrm{iodine,} 4.0 \\
\mu \mathrm{g} / 100 \mathrm{ml} \text {. }\end{array}$ \\
\hline J.B. & $\begin{array}{l}\text { Duchenne muscular } \\
\text { dystrophy }\end{array}$ & M & 19 & $\begin{array}{l}\text { Onset of weakness at age } 2 \text {. Unable to turn over in bed without } \\
\text { assistance. }\end{array}$ \\
\hline C.E. & $\begin{array}{l}\text { Duchenne muscular } \\
\text { dystrophy }\end{array}$ & M & 11 & $\begin{array}{l}\text { Half-brother to J.B., having the same mother. Onset of weak- } \\
\text { ness at age } 2 \text {. Had severe lordosis and walked with waddling } \\
\text { gait. }\end{array}$ \\
\hline R.G. & $\begin{array}{l}\text { Duchenne muscular } \\
\text { dystrophy }\end{array}$ & M & 11 & $\begin{array}{l}\text { Onset of weakness at age } 3 \text {. Could not walk but posture was } \\
\text { good. }\end{array}$ \\
\hline B.H. & $\begin{array}{l}\text { Facioscapulohumeral } \\
\text { muscular dystrophy }\end{array}$ & $\mathrm{F}$ & 35 & $\begin{array}{l}\text { Onset of weakness at age } 8 \text {. Prominent involvement of the facial } \\
\text { muscles and shoulder girdle. Severe lordosis and involvement } \\
\text { of the muscles of the pelvic girdle. }\end{array}$ \\
\hline
\end{tabular}

metabolism, the patients were provided routinely with constant diets including a limited amount of meat. To test the effect of variations in diet, short trials of a creatine-free diet were given two patients. B.H., with facioscapulohumeral muscular dystrophy, received a creatine-free diet from days 19 through 37, and H.G., with amyotrophic lateral sclerosis, received the same diet from days 5 through 20 and from days 111 through 122 of the turnover study. As a further test of the effect of dietary creatine on creatine turnover, H.G. received $14 \mathrm{~g}$ of unlabeled creatine in 1-g doses during a 10-day period from days 32 through 41 of the turnover study.

In addition to creatine loading, other causes of creatinuria were studied in R.B. and H.G., who did not have primary muscle disease, to see if there was an effect on the disappearance of radioactive urine creatinine. Methyltestosterone or triamcinolone acetonide was used to induce creatinuria. R.B. received $40 \mathrm{mg}$ of methyltestosterone orally every day from days 20 through 35 of his turnover study, but the drug had to be discontinued because of evidence of damage to the liver. H.G. was given $60 \mathrm{mg}$ of methyltestosterone orally every day from days 77 through 99 of the study. Then from days 153 through 157 , he was given $16 \mathrm{mg}$ of triamcinolone acetonide orally each day.

At the beginning of a turnover study, the patient received a single iv injection of creatine-1- $\mathrm{C}^{14}(2.62 \mu \mathrm{c}$ per $\mu$ mole). ${ }^{1}$ The doses of creatine-1- $\mathrm{C}^{\mathbf{1 4}}$ in microcuries were : R.B., 45 ; H.G., 63 ; H.C., 60 ; J.B., 28.6 ; C.E., 2.6 ; R.G., 25 ; and BH., 6.7. After the injection, serial blood samples were obtained, and the radioactivity of appropriate samples of a protein-free filtrate of the plasma was measured.

1 Purchased either from New England Nuclear Corp., Boston, Mass., or from Volk Radiochemical Company, Chicago, Ill.
Urine was collected daily for the isolation of creatine and creatinine. To minimize the interconversion of creatine and creatinine (16), urine was stored at $4^{\circ} \mathrm{C}$ during the 24-hour collection period, after which the isolation procedure was begun promptly. Creatinine was separated from creatine either by our method (17) modified to accommodate large volumes of urine or by the method of Benedict and associates (10) with minor modifications. That both methods completely remove creatine from creatinine $(10,17)$ was confirmed in the present experiments.

Urine creatinine free of creatine was obtained in every case, but creatine free of creatinine was prepared only from the urine of patients with massive creatinuria. In the three patients that excreted relatively little urine creatine (R.B., H.G., H.C.), significant amounts of preformed creatinine contaminated the creatine preparations. When creatine specific activity was calculated, appropriate corrections were made for the contamination by creatinine.

Creatinine was isolated as pure creatinine zinc chloride for the measurement of radioactivity (18). In certain instances creatinine picrate was prepared first, from which the creatinine zinc chloride was made (18), but the step involving the picrate was not necessary when carrier creatinine was used. Unlabeled carrier creatinine was routinely added before the isolation of creatinine zinc chloride except in the preparations from H.G. and B.H., which were obtained without dilution. Impurities other than creatine in the creatinine zinc chloride were excluded either by recrystallizing to constant radioactivity or by using the Folin method (19) to measure the amount of creatinine in the sample.

The specific activity of creatine was determined after its conversion to creatinine. Creatinine was formed from creatine by heating in the presence of hydrochloric acid. 


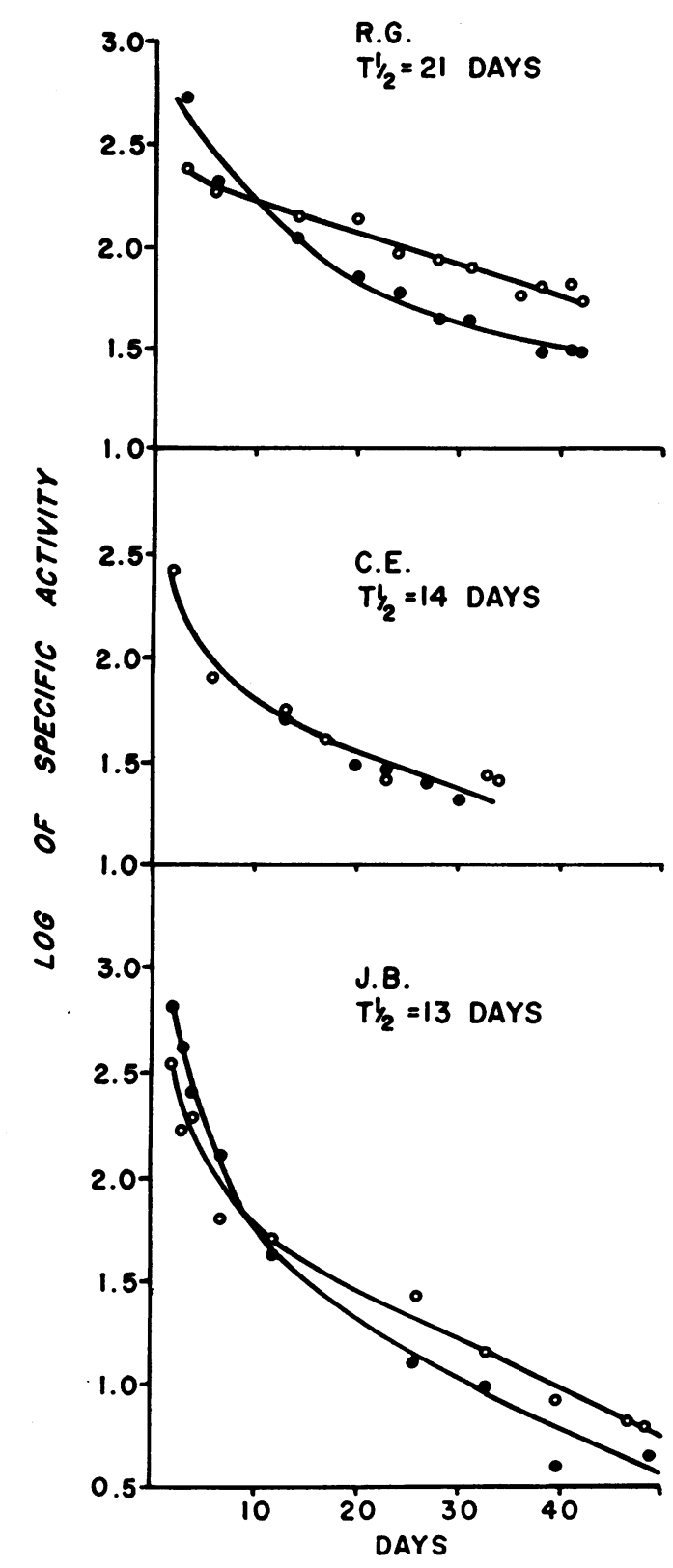

Fig. 1. Disappearance OF RADIOACTIVITY FROM URINE CReatine AND CREatinine in Patients With DuchenNe (PSEUDOHYPERTROPHIC) MUSCULAR DYSTROPHY. Solid circles represent creatine; open circles represent creatinine.

One-N solutions of hydrochloric acid containing the creatine were heated in an autoclave at $118^{\circ} \mathrm{C}$ for $45 \mathrm{~min}$ utes. Thereafter these solutions of creatinine were treated in the same manner as the preformed urine creatinine.

Creatine was isolated from biopsies of skeletal muscle as creatinine zinc chloride by a previously described method involving the addition of carrier creatinine (20). A sample of urine creatinine obtained during the day of the biopsy was isolated in a comparable manner so that direct comparison of counting rates could be made. The biopsies were taken from areas of obvious muscle wasting.

The radioactive samples were counted either with an ultrathin window continuous gas flow Geiger tube or with a windowless gas flow Geiger tube. All the samples from each patient were counted with the same system; the probable error of counting did not exceed $2 \%$. The creatinine zinc chloride was counted at infinite thickness, or the weight used was always the same for an individual patient. Specific activity is recorded as counts per minute per weight of the creatinine zinc chloride. The specific activities recorded for one patient are not directly comparable to another, because neither the dose of creatine-1-C $\mathrm{C}^{\mathbf{1 4}}$, the dilution by unlabeled creatinine, nor the sample weight of creatinine zinc chloride was the same for every patient.

Muscle creatine concentration was measured by the method of Rose, Helmer, and Chanutin (21). Urine creatine and creatinine concentrations were measured by the Folin procedure (19) with minor modifications. Both methods measure creatine as creatinine.

\section{Results}

The rate of disappearance of radioactivity from urine creatinine after the injection of creatine$1-C^{14}$ was most rapid in the patients with muscular dystrophy. This is apparent from a comparison of the graphs showing the change of creatinine specific activity with time (Figures $1-6)$. The half-times for the decrease of urine creatinine specific activities were 13 to 21 days in the patients with Duchenne (pseudohypertrophic) muscular dystrophy, 23 days in the patient with facioscapulohumeral muscular dystrophy, 49 days in the patient with a late onset myopathy, 39 days in the patient with amyotrophic

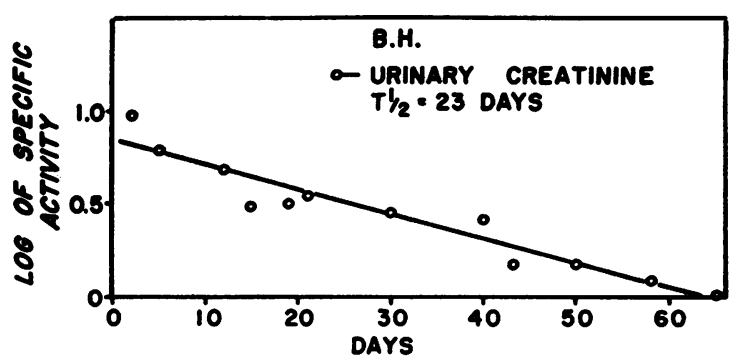

Fig. 2. DisAPPEARANCE OF RADIOACTIVITY FROM URINE CREATININE OF A PATIENT WITH FACIOSCAPUlOHUMERAL MUSCULAR DYSTROPHY. This patient received a creatinefree diet from days 19 through 37. 


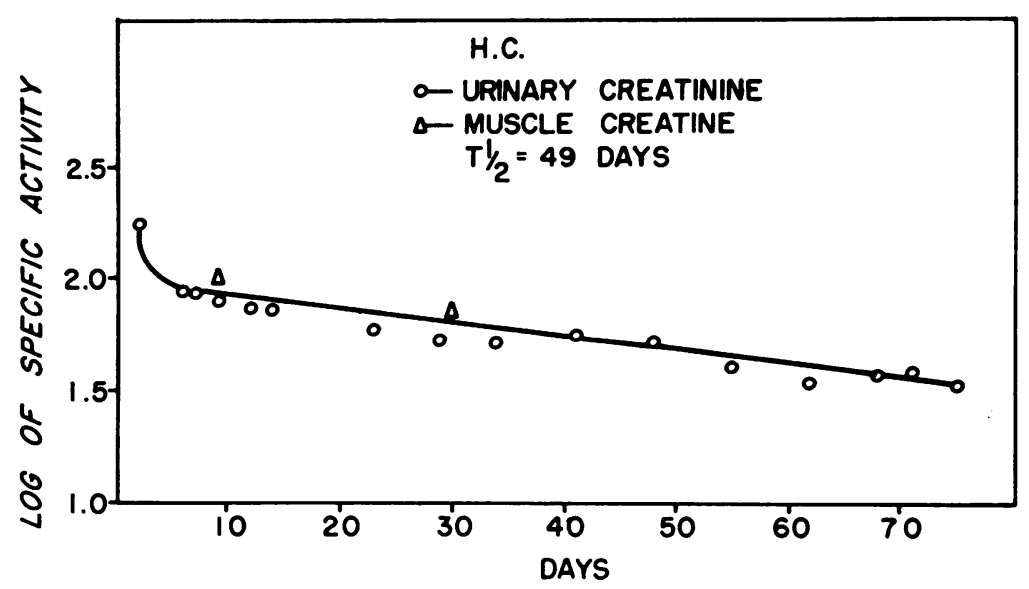

Fig. 3. Disappearance of Radioactivity From URINe CREATinine of a PATIENT With a myopathy of late onset. For comparison the specific activities of muscle creatine at days 9 and 30 are shown.

lateral sclerosis, and 38 days in the patient with no abnormality of muscle.

None of the attempts to change blood creatine concentration and to induce creatinuria caused a permanent change in urine creatinine specific activity (Figures 2, 4-6). Creatine feeding by expanding extramuscular pools of creatine caused a temporary lowering of creatinine isotope content (Figure 5), as has been observed by others (15). Changing from a meat-free to a meatcontaining diet had no significant effect (Figures $2,4,5)$. Neither did methyltestosterone nor triamcinolone acetonide therapy affect the specific activity of urine creatinine, although both drugs induced creatinuria, most probably by increasing creatine synthesis $(22,23)$.

The specific activities of muscle creatine and urine creatinine were similar, with muscle creatine specific activity being slightly higher (Table II). However, in one patient, J.B., a wide difference in the two specific activities was observed. The biopsy was taken from this patient on the eighth day while urine creatine and creatinine specific activities were changing rapidly (Figure 1). The similarity of the specific activities of urine creatinine and muscle creatine is remarkable in view of the small sample of muscle creatine used. Of additional significance is the fact that in the patient with a late onset myopathy the specific activity of muscle creatine and its rate of change were similar to the same measurements of urine creatinine (Figure 3). These observations are in agreement with the assumption that creatinine is derived primarily from muscle creatine.

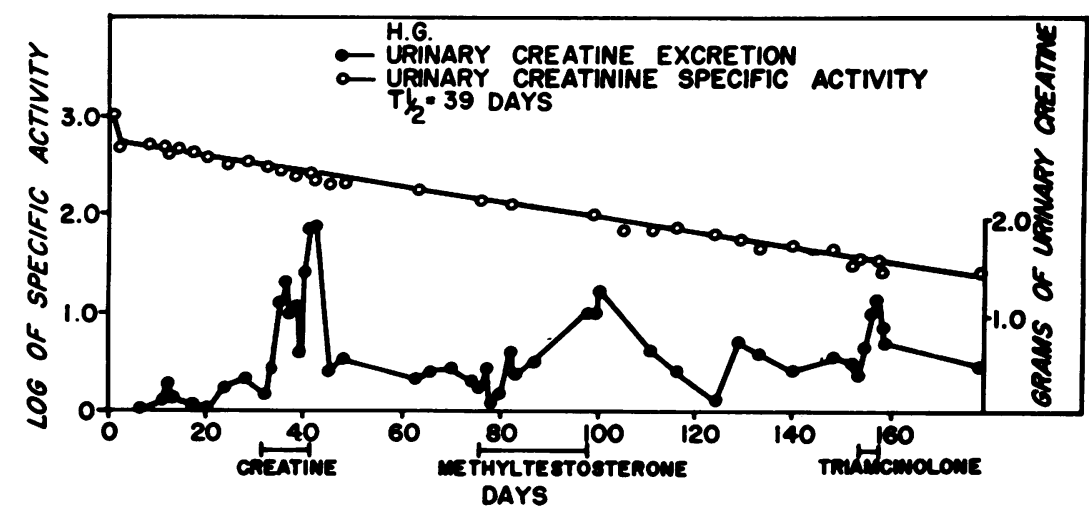

Fig. 4. Creatine EXCRETION AND THE DisApPeARANCE OF RADioactivity From URINE CREATININE OF A PATIENT With AMYOTROPHIC LATERAL SClERosis. 


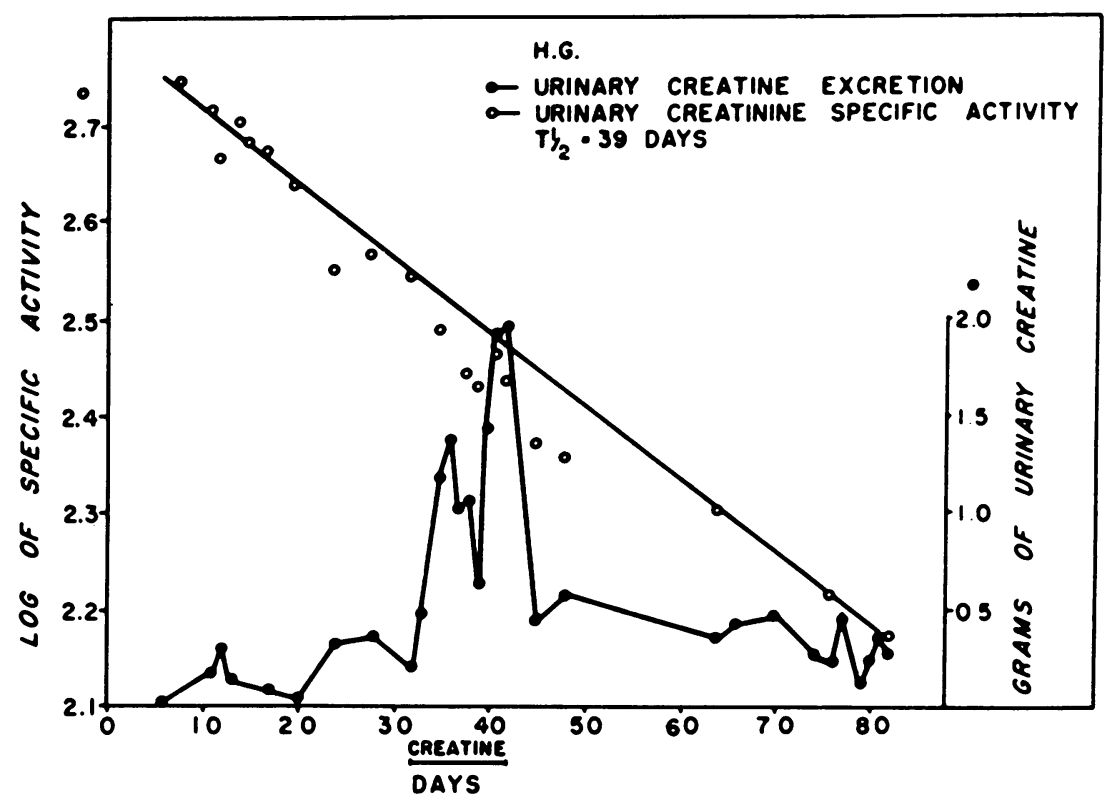

Fig. 5. The EFFECT OF CREATINe FEEding ON THE disappearance OF RadioACTIVITY FROM URINE CREATININE. This patient received a creatine-free diet from days 5 through 20 .

The specific activity of urine creatine of each patient was measured several times. The largest quantities of radioactive urine creatine were excreted by the patients with muscular dystrophy. In those with Duchenne muscular dystrophy the rate of decrease of urine creatine specific activity at the late time intervals was identical to that of creatinine, 13 to 21 days (Figure 1 ). The urine creatine specific activity was usually lower than that of creatinine, but because of the large quantities of creatine, more radioactivity was present in

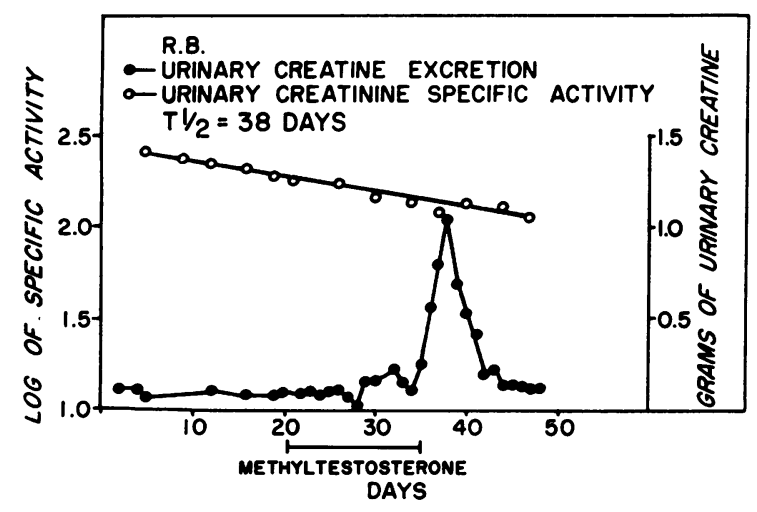

Fig. 6. Creatine excretion and the disappearANCE OF RADIOACTIVITY FROM URINE CREATININE OF A PATIENT WITH NORMAL MUSCLE FUNCTION. creatine than in creatinine. Limited data from late time intervals, using the carrier isolation technique, showed that the urine creatine specific activity was almost the same as that of creatinine in the patient with facioscapulohumeral muscular dystrophy.

In the patient with a late onset myopathy the urine creatine and creatinine specific activities were similar at 4 days, but no urine creatine samples isolated after the twelfth day contained radioactivity. By contrast the specific activity of urine creatine excreted after methyltestosterone therapy was $40 \%$ of that of creatinine on days 37 and 40 in the patient who had no abnormality of muscle. Another patient, H. G., with amyotrophic lateral sclerosis, excreted radioactive crea-

TABLE II

Comparison of muscle creatine and urine creatinine specific activities

\begin{tabular}{lccc}
\hline \hline Patient & $\begin{array}{c}\text { Days after } \\
\text { injection }\end{array}$ & $\begin{array}{c}\text { Muscle } \\
\text { creatine }\end{array}$ & $\begin{array}{c}\text { Urine } \\
\text { creatinine }\end{array}$ \\
\hline H.C. & 9 & 100 & 75 \\
H.C. & 30 & 71 & 53 \\
J.B. & 8 & 140 & 59 \\
H.G. & 14 & 25 & 24 \\
R.G. & 31 & 14 & 11 \\
\hline
\end{tabular}




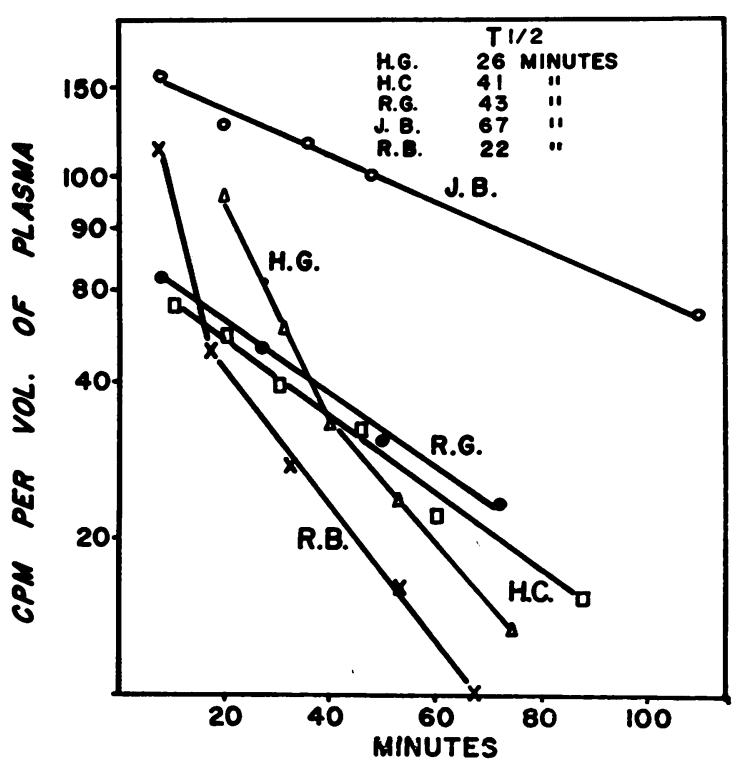

Fig. 7. Disappearance of CReatine-1-C ${ }^{14}$ From the PLASMA. The diagnoses were: H.G., amyotrophic lateral sclerosis; H.C., late onset myopathy; R.G. and J.B., pseudohypertrophic muscular dystrophy; and R.B., primary refractory anemia.

tine without any therapy to induce creatinuria. His urine creatine specific activity was the same as that of creatinine on day 28 and approximately one-half as much as that of creatinine on day 129.

The specific activity of plasma creatine was not determined, but the rate of disappearance of creatine- $\mathrm{C}^{14}$ from the plasma was measured and is shown in Figure 7 . The plasma creatine halftime estimated from these measurements varied from 22 to 67 minutes. This is the order of magnitude that would be predicted from the daily ex- cretion of creatinine and the usual concentration of creatine in the plasma. The shortest halftimes occurred in the subjects with the least excretion of creatine. This probably reflects only lower concentrations of plasma creatine.

During these studies the concentration of creatine in muscle and the excretion of creatine and creatinine in the urine were routinely measured. Much of this data is summarized in Table III. The concentration of creatine in muscle is based on wet weight, but a reduction in concentration has been observed by others who have used noncollagen nitrogen as the reference base $(8,9)$.

Urine excretion of creatinine was low, and excretion of creatine was increased in the patients with muscular dystrophy. Excretion of creatine by the patient with the late onset myopathy was inconstant, but the average daily excretion was slightly increased. For comparison, data on the excretion of creatine by R.B. and H.G., who did not have primary muscle disease, are presented in Table III as well as in Figures 4-6. R.B. did not have creatinuria even with meat in his diet until methyltestosterone was given. H.G. had no creatinuria when he received a meat-free diet, but excessive excretion of creatine began promptly when meat was included.

\section{Discussion}

Creatine turnover studies have been done previously in two adults $(15,22)$. The chief difference between these early studies and ours was in the isotope used to label creatine. Creatine was labeled with $\mathrm{N}^{15}$ in the first studies and with

TABLE III

Muscle creatine concentration and urine excretion of creatine and creatinine

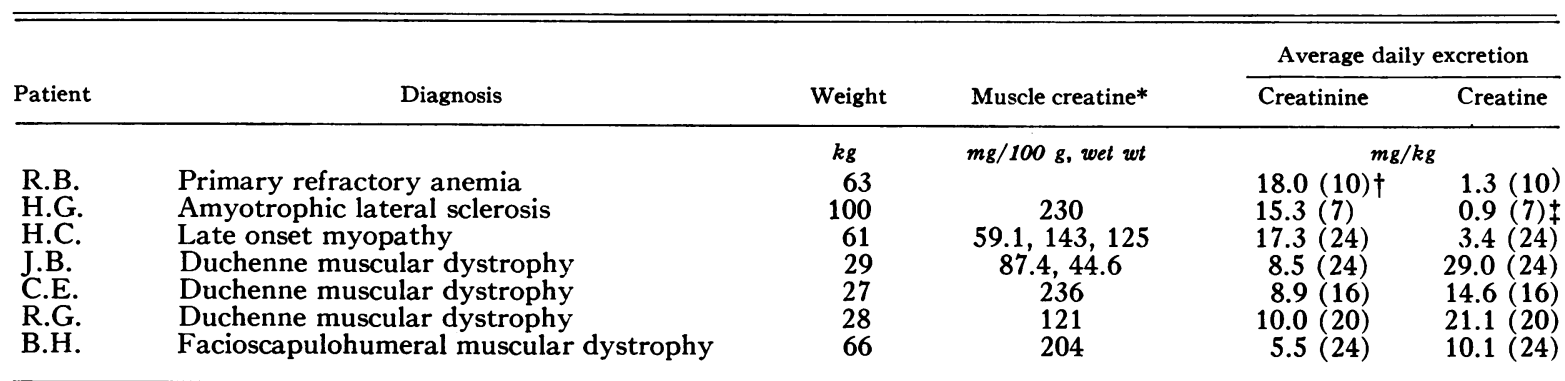

* All biopsies were from the gastrocnemius except for H.C., from whom a biopsy from the biceps and two from the deltoids were taken.

$\dagger$ The number of days included in the average is given in parentheses.

$\ddagger$.G. was on a creatine-free diet during these urine collections. 
$\mathrm{C}^{14}$ in ours. The half-time for the decrease in isotope content of urine creatinine, which at late time intervals reflects the changing isotope content of muscle creatine, was 42 days for each of the subjects in the early studies. This compares with the half-time of 38 days in our patient with normal muscle function (R.B.). There is no reason to suspect that the half-time is normally ever significantly less than that found in these three subjects. In experiments in rats and monkeys we have found no major influence of age or sex on the turnover of muscle creatine (24). In normal animals, studies of creatine turnover have yielded half-times of 38 to 51 days in the Macaca mulatta monkey (24) and 30 to 35 days in the rat $(25,26)$. The half-time is probably 38 days in the $\operatorname{dog}(27)$; in the mouse, despite the normal excretion of large amounts of creatine, the halftime is 20 days (17).

An important aspect of the present studies facilitating interpretation of the data was the use of patients with various types of muscle wasting. The patient with amyotrophic lateral sclerosis (H.G.) and the one with a late onset myopathy (H.C.) are in some ways better than normal subjects as controls for the patients with muscular dystrophy. In contrast to half-times of 39 and 49 days for the decrease in urine creatinine specific activity for H.G. and H.C., respectively, the patients with Duchenne and facioscapulohumeral muscular dystrophy had much shorter half-times of 13 to 23 days. Although all of these diseases cause creatinuria and low concentrations of muscle creatine, the defects in the metabolism of creatine in Duchenne and facioscapulohumeral muscular dystrophy are evidently different from those of the two other types of muscle wasting.

One explanation for the short half-time in muscular dystrophy might be dilution of body creatine as a result of rapid regeneration of muscle. This would not account for the low concentration of muscle creatine, nor is it likely that regeneration of muscle in muscular dystrophy occurs at such a rapid rate (28). The low concentration of muscle creatine points to a defect in creatine metabolism by surviving muscle.

The low concentration of creatine could be due to a decreased rate of entry of creatine, to an impaired ability of muscle to retain creatine, or to a combination of both possibilities. A de- creased rate of entry of creatine into muscle would not explain the short half-time of the decrease in urine creatinine specific activity, the high specific activity of urine creatine, and the parallel decrease in urine creatine and creatinine specific activities at the late time intervals in the patients with Duchenne muscular dystrophy; whereas an impaired ability of muscle to retain creatine, together with a normal or increased rate of entry of creatine, would account for all of these observations. To understand the reason for the abnormal loss of creatine from muscle, further information about the mechanism responsible for maintaining the concentration gradient between muscle and plasma is needed.

Certain of our observations suggest that the gradient is not associated with rapid entry of creatine into muscle. On the contrary, mixing of creatine across the muscle membrane appears to be quite limited. In two patients the amount of creatine in the diet did not affect the rate of change of urine creatinine specific activity. Likewise, other causes of creatinuria, i.e., methyltestosterone and triamcinolone acetonide therapy, did not permanently lower urine creatinine specific activity. Similar observations were not made in patients with muscular dystrophy. However, mixing of creatine across the muscle membrane must be limited even in muscular dystrophy, where increased membrane permeability may occur (29). This is made evident by the different specific activities of urine creatine and creatinine in two of our patients (Figure 1) and by the findings of Benedict and associates (10).

The foregoing observations do not exclude the normal loss from skeletal muscle of small amounts of creatine before its conversion to creatinine. Indeed, the radioactive creatine in the urine of R.B. after methyltestosterone and in the urine of H.G. at the late time intervals indicates the loss of small amounts of creatine from muscle. Creatine coming from muscle would contribute radioactive creatine to extramuscular pools. With radioactive creatine outside of muscle, methyltestosterone or other factors could cause excessive excretion of creatine, some of which would be radioactive, without affecting the half-time of muscle creatine, and this is what we found.

If the membrane permits the diffusion of creatine out of muscle despite a slow rate of entry, 
then creatine must be bound within the muscle. Much of the creatine in muscle is present as phosphocreatine, which should not diffuse across the membrane, but the concentration of phosphocreatine is not high enough to account for the gradient between muscle and plasma. Another explanation is suggested by the postulate of Lee and Visscher that there is an unidentified substance in cardiac muscle that binds creatine (30).

Defective synthesis or accelerated loss of a binding substance, possibly a protein, would explain the abnormal metabolism of creatine by skeletal muscle in muscular dystrophy. The binding substance is hypothetical, but regardless of the mechanism involved, the abnormal loss of creatine from muscle could represent a specific genetic defect. Because of the unusual concentration of creatine normally in muscle and in view of the role of phosphocreatine in energy metabolism, this defect could be of primary importance in muscular dystrophy.

\section{Summary}

The half-time of the decrease in urine creatinine specific activity after an iv injection of creatine$1-C^{14}$ was 38 days in a subject with normal muscle function and 39 days in a patient with amyotrophic lateral sclerosis. Similar studies in a patient with a myopathy of late onset gave a half-time of 49 days. By contrast, half-times of 13,14 , and 21 days in patients with Duchenne (pseudohypertrophic) muscular dystrophy and 23 days in a patient with facioscapulohumeral muscular dystrophy were found. Skeletal muscle creatine specific activity was similar to that of urine creatinine at several time intervals, confirming the common assumption that the disappearance of radioactive urine creatinine reflects the disappearance of radioactive creatine from the muscle.

The isotope content of urine creatine from the patients with Duchenne muscular dystrophy was either identical to or parallel to that of urine creatinine. This together with the short halftime led to the conclusion that the low concentration of creatine in skeletal muscle in Duchenne muscular dystrophy is due to an inability of muscle to retain creatine. To explain this abnormality, we suggest that there is defective synthesis or accelerated loss of a substance that normally binds creatine within the muscle.

\section{Acknowledgments}

We are indebted to Dr. James S. Dinning for advice and encouragement throughout this investigation, to Miss Cecilia Hsu for valuable technical assistance, and to Dr. Dennis Lucy for performing the muscle biopsies.

\section{References}

1. Borsook, H., and J. W. Dubnoff. The hydrolysis of phosphocreatine and the origin of urinary creatinine. J. biol. Chem. 1947, 168, 493.

2. Van Pilsum, J. F., and M. Bovis. Effect of various protein precipitants on recoveries of creatinine added to plasma. Clin. Chem. 1957, 3, 90.

3. Conn, R. B., Jr. Fluorimetric determination of creatine. Clin. Chem. 1960, 6, 537.

4. Milhorat, A. T. Creatine and creatinine metabolism and diseases of the neuro-muscular system in Metabolic and Toxic Diseases of the Nervous System, H. H. Merritt and C. C. Hare, Eds. Ass. Res. nerv. Dis. Proc. 1953, 32, 400.

5. Cooper, A. C., and J. R. Miller. Progressive muscular dystrophy: a review. Rev. canad. Biol. 1962, 21, 337.

6. Dreyfus, J. C., and G. Schapira. Biochemistry of Hereditary Myopathies. Springfield, Ill., Charles C Thomas, 1962, p. 43.

7. Bourdakos, N., and S. Wolf. Creatine and muscular dystrophy. Relationship of creatine-creatinine metabolism to diet and drugs. Arch. Neurol. (Chic.) 1962, 6, 439.

8. Ronzoni, E., S. Wald, L. Berg, and R. Ramsey. Distribution of high energy phosphate in normal and dystrophic muscle. Neurology (Minneap.) 1958, 8, 359.

9. Vignos, P. J., Jr., and J. L. Warner. Glycogen, creatine, and high energy phosphate in human muscle disease. J. Lab. clin. Med. 1963, 62, 579.

10. Benedict, J. D., H. J. Kalinsky, L. A. Scarrone, A. R. Wertheim, and D. Stetten, Jr. The origin of urinary creatine in progressive muscular dystrophy. J. clin. Invest. 1955, 34, 141.

11. Van Pilsum, J. F., and B. Hiller. On the proposed origin of creatinine from creatine phosphate. Arch. Biochem. 1959, 85, 483.

12. Bloch, K., and R. Schoenheimer. Studies in protein metabolism. XI. The metabolic relation of creatine and creatinine studied with isotopic nitrogen. J. biol. Chem. 1939, 131, 111.

13. Du Vigneaud, V., M. Cohn, J. P. Chandler, J. R. Schenck, and S. Simmonds. The utilization of the methyl group of methionine in the biological synthesis of choline and creatine. J. biol. Chem. $1941,140,625$.

14. Mackenzie, C. G., and V. Du Vigneaud. Biochemical stability of the methyl group of creatine and creatinine. J. biol. Chem. 1950, 185, 185.

15. Hoberman, H. D., E. A. H. Sims, and J. H. Peters. Creatine and creatinine metabolism in the normal 
male adult studied with the aid of isotopic nitrogen. J. biol. Chem. 1948, 172, 45.

16. Tanzer, M. L., and C. Gilvarg. Creatine and creatine kinase measurement. J. biol. Chem. 1959, 234, 3201.

17. Fitch, C. D., J. D. Oates, and J. S. Dinning. The metabolism of creatine-1- $\mathrm{C}^{\mathbf{1 4}}$ by mice with hereditary muscular dystrophy. J. clin. Invest. 1961, 40,850 .

18. Hawk, P. B., B. L. Oser, and W. H. Summerson. Practical Physiological Chemistry, 12th ed. Philadelphia, Blakiston, 1949, p. 733.

19. Folin, $O$. On the determination of creatinine and creatine in urine. J. biol. Chem. 1914, 17, 469.

20. Dinning, J. S., and C. D. Fitch. Creatine metabolism in vitamin E deficiency. Proc. Soc. exp. Biol. (N. Y.) 1958, 97, 109.

21. Rose, W. C., O. M. Helmer, and A. Chanutin. A modified method for the estimation of total creatinine in small amounts of tissues. J. biol. Chem. $1927,75,543$.

22. Hoberman, H. D., E. A. H. Sims, and W. W. Engstrom. The effect of methyltestosterone on the rate of synthesis of creatine. J. biol. Chem. 1948, 173, 111.

23. Perkoff, G. T., R. Silber, F. H. Tyler, G. E. Cartwright, and M. M. Wintrobe. Studies in dis- orders of muscle. XII. Myopathy due to the administration of therapeutic amounts of 17-hydroxycorticosteroids. Amer. J. Med. 1959, 26, 891.

24. Fitch, C. D., and J. S. Dinning. Unpublished data.

25. Bloch, K., R. Schoenheimer, and D. Rittenberg. Rate of formation and disappearance of body creatine in normal animals. J. biol. Chem. 1941, 138, 155.

26. Cohn, M., S. Simmonds, J. P. Chandler, and V. Du Vigneaud. The effect of the dietary level of methionine on the rate of transmethylation reactions in vivo. J. biol. Chem. 1945, 162, 343.

27. Anderson, E., L. H. Kedda, and K. Knowlton. A preliminary investigation of the source of the creatinuria following transection of the spinal chord. Proc. Soc. exp. Biol. (N. Y.) 1962, 110, 690.

28. Denny-Brown, D. Degeneration of skeletal muscle. Rev. canad. Biol. 1962, 21, 507.

29. Dreyfus, J. C., J. Kruh, and G. Schapira. Muscular protein metabolism in diseased states in Protein Metabolism, F. Gross, Ed. Berlin, Springer, 1962, p. 326.

30. Lee, Y. C. P., and M. B. Visscher. On the state of creatine in heart muscle. Proc. Nat. Acad. Sci. (Wash.) 1961, 47, 1510. 